\title{
Differential effects of a computerized cognitive stimulation program on older adults with mild cognitive impairment according to the severity of white matter hyperintensities
}

This article was published in the following Dove Press journal:

Clinical Interventions in Aging

\author{
Leila Djabelkhir-Jemmi ${ }^{1,2}$ \\ Ya-Huei Wu',2 \\ Marouane Boubaya ${ }^{3}$ \\ Fabienne Marlats ${ }^{1,2}$ \\ Manon Lewis' \\ Jean-Sébastien Vidal ${ }^{1,2}$ \\ Hermine Lenoir ${ }^{1,2}$ \\ Benoit Charlieux' \\ Baptiste Isabet' \\ Anne-Sophie Rigaud ${ }^{1,2}$ \\ 'Department of Clinical Gerontology, \\ Broca Hospital-APHP, Paris, France; \\ ${ }^{2}$ Research Team EA 4468, Alzheimer's \\ Disease, Vascular Risk Factors and \\ Diagnostic Markers, Care and Support \\ for Patients and Families, Institute \\ of Psychology of Paris Descartes \\ University, Paris, France; ${ }^{3}$ Clinical \\ Research Unit, Avicenne Hospital, \\ Bobigny, France
}

\begin{abstract}
Objective: This study aimed to explore whether a computerized cognitive stimulation program (CCS) induced differential effects in older adults with mild cognitive impairment (MCI) according to the severity of white matter hyperintensities (WMH), which are associated with cognitive impairment and increased risk of progression to Alzheimer's disease because of the damage they cause to cortical and subcortical networks.

Patients and methods: Twenty-nine MCI patients with no or little WMH (MCI-non-WMH) and $22 \mathrm{MCI}$ patients with moderate or severe WMH (MCI-WMH) attended a 24-session CCS program (two sessions per week for a duration of 3 months) focused on executive functions, attention, and processing speed. Cognitive and psychosocial assessments were performed at baseline, postintervention, and 3 months after the intervention.

Results: Both groups improved on several cognitive measures after the intervention. However, the MCI-non-WMH group improved on a higher number of cognitive measures than the MCI-WMH group. At postintervention assessment, CCS had a more beneficial effect on the MCI-non-WMH group than on the MCI-WMH group with regard to improving categorical fluency ( $4.6 \pm 6.8$ vs $0.4 \pm 6.4$; effect size $=0.37 ; p=0.002$ ). During the 3 -month follow-up assessment, significantly higher score improvements were observed in the MCInon-WMH group for the paired-associate learning test $(6.4 \pm 3$ vs $4.7 \pm 3.5$ points; effect size $=0.43 ; p=0.005)$ as well as categorical fluency $(3.8 \pm 7.8$ vs $-0.7 \pm 6$ points; effect size $=0.55$; $p=0.0003$ ).
\end{abstract}

Conclusions: These findings suggest that WMH severity was related to cognitive improvement induced by a CCS program and highlight the importance of considering WMH in interventional studies on subjects with MCI.

Keywords: white matter hyperintensities, mild cognitive impairment, computerized cognitive interventions, brain lesions, Alzheimer's disease

\section{Introduction}

Mild cognitive impairment (MCI) is commonly regarded as being a transitional phase between normal aging and early Alzheimer's disease (AD), the most common cause of dementia. Older adults with MCI have a higher risk of developing dementia $\left(10 \%-15 \%\right.$ per year), ${ }^{1}$ compared to the general older population ( $1 \%-2 \%$ per year). ${ }^{2}$ In the absence of effective treatment for dementia, MCI is becoming of interest for pharmacologic and nonpharmacologic interventions, in order to prevent further cognitive decline.
Correspondence: Leila Djabelkhir-Jemmi Hôpital Broca, Assistance Publique Hôpitaux de Paris (AP-HP) and EA 4468, Université Paris Descartes, Paris, France Tel +33 I4 4083507

Fax +33 I4 4083510

Email leila.djabelkhir@gmail.com 
It is now well established that cognitive interventions such as cognitive training, cognitive rehabilitation, and cognitive stimulation $^{3}$ could help maintain or enhance cognitive and functional abilities in MCI subjects. ${ }^{4,5}$ The last decade has seen the emergence of various computerized cognitive intervention programs, which seem promising for these patients. ${ }^{6-9} \mathrm{Com}-$ puterized programs involve both cognitive training and novel learning experiences. On one hand, participants are required to focus on tasks tapping into either multiple or specific cognitive domains. On the other hand, older adults who are not familiar with digital devices need to acquire new skills, which in turn stimulates several cognitive functions. ${ }^{10}$ However, there is a lack of consensus regarding their efficacy, in part due to the heterogeneity of MCI, a factor that may affect intervention outcome..$^{4,5,11,12} \mathrm{MCI}$ is a heterogeneous clinical entity, encapsulating different cognitive profiles, underlying brain pathologies and follow-up outcomes. In most of the studies on cognitive interventions in $\mathrm{MCI}$, underlying brain lesions are rarely taken into consideration. However, it has been suggested that MCI patients with more severe brain lesions might benefit less or differently from cognitive interventions than those with less severe brain lesions. ${ }^{9}$

In biologic terms, $\mathrm{AD}$ is commonly defined as the accumulation of beta-amyloid protein and the deposition of neurofibrillary tangles. However, increasing evidence shows that white matter hyperintensities (WMH) also contribute to the development of MCI and AD. ${ }^{13,14} \mathrm{WMH}$ are visualized as increased signal on T2-weighted fluid-attenuated inversion recovery magnetic resonance imaging (MRI) sequences. WMH are often considered to be markers of cerebral small-vessel disease and are frequently observed in older adults with MCI and AD. ${ }^{15,16}$ It is hypothesized that WMH might precipitate the clinical manifestation of MCI and AD. ${ }^{17,18}$ Neuroimaging studies have shown that WMH may cause a frontal-subcortical pathway disruption, leading to executive, attentional, and processing speed impairment ${ }^{19-21}$ as well as memory deficits, due to retrieval impairment. ${ }^{17,22,23} \mathrm{WMH}$ have been observed in amnestic and nonamnestic subtypes of MCI. ${ }^{15,17,24,25}$

To address the lack of literature regarding the effects of cognitive intervention programs according to brain lesions, this study aimed to compare effects of a computerized cognitive stimulation (CCS) program in MCI patients according to the severity of WMH.

\section{Patients and methods Design}

This is a prospective, single-blind, parallel-group, quasiexperimental study. The flow chart of the study is reported in Figure 1.

\section{Participants}

Participants were recruited in Broca Hospital's memory clinic between 2015 and 2016.

To be included in the study, participants must have had 1) a diagnosis of $\mathrm{MCI}:{ }^{26}$ subjective memory complaints, preferably corroborated by an informant, objective impairment on more than one of the neuropsychological tests used in the memory clinic (French version of the Free and Cued Selective Reminding Test, ${ }^{27}$ Frontal Assessment Battery, ${ }^{28}$ Digit Span, ${ }^{29}$ verbal fluency, ${ }^{30}$ Trail Making Test parts A and B [TMT-B], ${ }^{31}$ 80 -item naming test, ${ }^{32}$ Praxic Ability Scale, ${ }^{33} 1.5$ SD below the mean for age and education or below the cutoff score), preserved global intellectual function, preserved or minimal impairment in daily living activities, and the absence of dementia; 2) MRI evidence indicating the severity of WMH. The severity of WMH was estimated by an experienced neurologist using the Fazekas Scale, ${ }^{34}$ providing two different scores for periventricular WMH and deep WMH, rated on four points (0-3). Periventricular WMH were rated as $0=$ no lesions; 1="caps" or pencil-thin lining; 2=smooth "halo"; and $3=$ irregular lesions extending into the deep white matter. Deep WMH were rated as $0=$ no lesions; $1=$ punctuate foci; $2=$ beginning confluence of foci; and $3=$ large confluent areas. We classified participants into two groups according to the severity of $\mathrm{WMH}$, taking into account both periventricular and deep WMH: MCI subjects with no or little WMH (MCInon-WMH; grade 0 and 1) vs MCI subjects with moderate to severe WMH (MCI-WMH; grades 2 and 3).

The exclusion criteria were 1) psychiatric and neurologic disorders (eg, bipolar disorder, Parkinson's disease, epilepsy); 2) history of alcohol or other substance abuse; 3 ) sensory and/or motor deficits that could interfere with the use of a digital device; 4) participation in another intervention. Two hundred and twenty-five patients were screened. Of the 58 participants eligible for the study, seven subjects dropped out (three participants without WMH and four with WMH), yielding 51 patients who completed the intervention program ( 39 women and 12 men; age=75.3 \pm 6.2 years) as well as preand postintervention assessments. Fourteen participants did not complete the follow-up assessment (seven MCI-WMH and seven MCI-non-WMH). Written informed consent was obtained from all participants. This study was approved by the ethical committee from Paris Descartes University's Institutional Review Board ( $\mathrm{N}^{\circ}$ IRB: 20161300001072) and was registered at ClinicalTrials.gov as NCT03195803.

\section{Intervention}

All participants benefited from the same CCS program, developed using the concept of cognitive stimulation, ${ }^{35-37}$ 


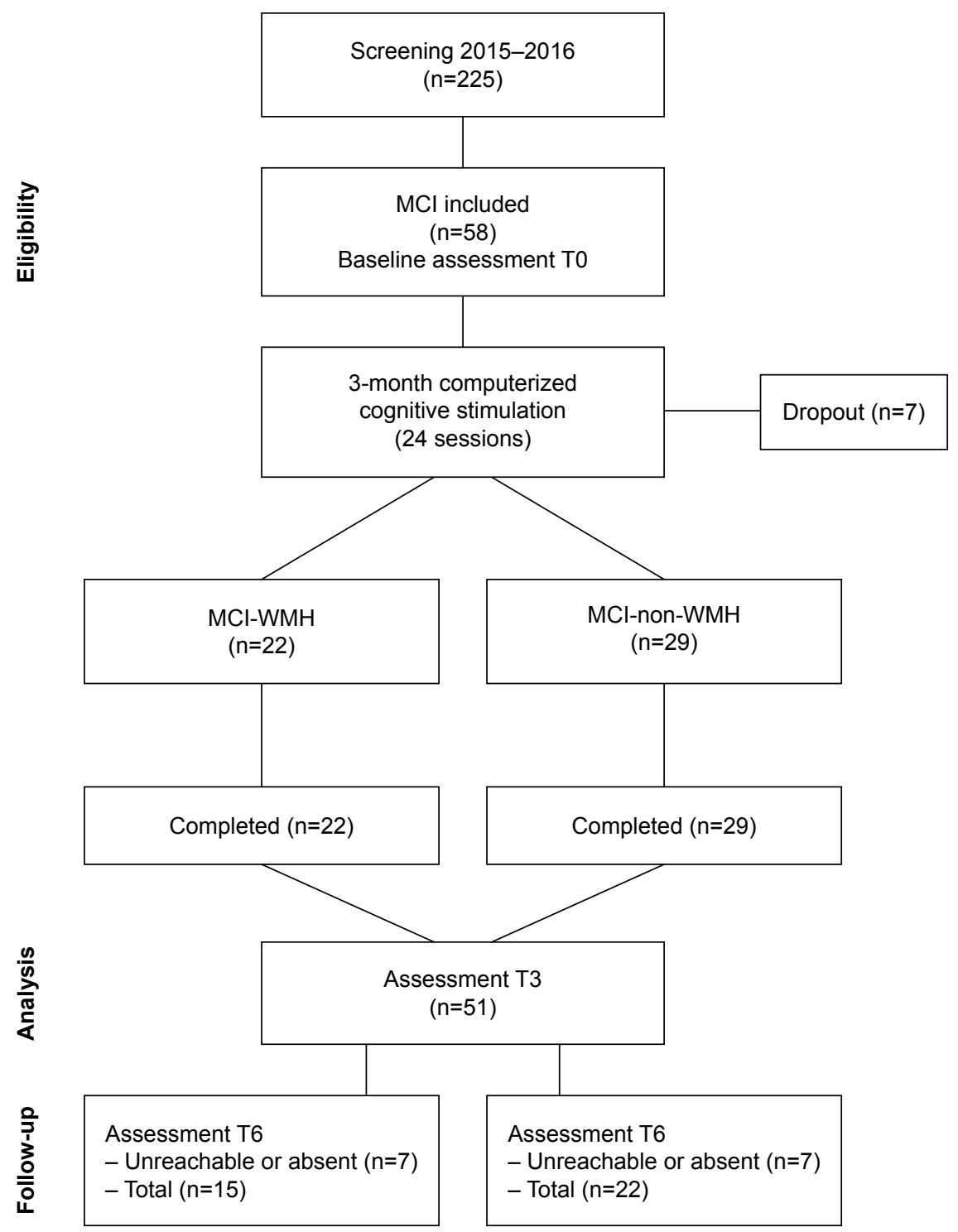

Figure I The flow chart of the study.

Notes: T0, baseline; T3, postintervention; T6, 3-month follow-up after the intervention.

Abbreviations: $\mathrm{MCl}$, mild cognitive impairment; $\mathrm{MCl}-\mathrm{WMH}, \mathrm{MCl}$ with moderate or severe white matter hyperintensities; $\mathrm{MCl}$-non-WMH, $\mathrm{MCl}$ with no or little white matter hyperintensities.

an ecologic approach based on engaging participants in a range of cognitive exercises in a group setting, thus aiming to stimulate cognitive functions and promote social interactions. The participants attended a 1 and a half hour session twice a week, during a period of 3 months ( 24 sessions in total) in Broca hospital. Three experienced neuropsychologists conducted group sessions with five to seven participants per group.

The cognitive exercises were selected from the "KODRO" software (Altera-Group, Paris, France), a web-based platform, developed for older adults. We chose KODRO for its large content of playful cognitive exercises and for the ecologic nature of some of the exercises, which can be applied in everyday life. These cognitive exercises targeted several cognitive processes, such as mental flexibility, processing speed, working memory, planning/organization, categorization, attention, reaction time, inhibition, and visual tracking. An example of one of these exercises is "Instruction" (tapping into mental flexibility, divided attention, and processing speed), which consists in touching specific stimuli (with different shapes and colors), among multiple distractors, as quickly as possible within the time allocated (indicated by a countdown timer). Within this series of exercises, participants must pay attention to the countdown timer while touching target stimuli. At the end of each countdown timer, instructions change and participants are then required to touch stimuli of another color and shape. Neuropsychologists managed the sessions and the difficulty level of the exercises, thanks 
to an iPad linked to a TV screen and to each participant's tablet-PC. The neuropsychologist's iPad displayed the success and failure rate for each exercise, and participants' tablet-PCs display feedback (good, very good, and excellent) at the end of each step of the exercise, in order to encourage them. The TV screen displayed the date at the beginning of the session and the instructions for each exercise, allowing the participants to refer to them when necessary. The content of the exercises was scheduled to change every 2 weeks.

During the first session, the participants introduced themselves. Explanations about the outline of the program were given. They were trained to use some basic functionalities of a tablet-PC.

The remaining sessions were structured as follows:

- Greeting and discussion about personal events and the news, to foster exchanges before cognitive exercises (5 minutes).

- Cognitive exercises with a tablet-PC: four 15-minute cognitive exercises (60 minutes).

- Brief conclusion/debriefing with feedback about the session ( 5 minutes).

\section{Outcomes}

Participants were assessed at baseline (T0), immediately after the 3-month intervention (T3) and during a 3-month follow-up postintervention (T6). Neuropsychologists involved in data collection at any point of the assessment process were blinded to which group participants were part of. Outcomes were composed of neuropsychological and psychosocial measures.

At baseline, we collected sociodemographic data such as age and sex as well as education level and premorbid intelligence, as assessed by the French adaptation of the National Adult Reading Test. ${ }^{38}$ The presence or absence of hippocampal atrophy was also recorded.

\section{Neuropsychological measures}

- Mini Mental State Evaluation (MMSE) ${ }^{39}$ assessing global cognitive efficiency (score range: 0-30).

- Rey Auditory Verbal Learning Test (RAVLT) ${ }^{40}$ for the assessment of episodic memory. Two scores were used: the sum of all correct immediate recall scores across five consecutive trials (score range: $0-75$ ) and the delayed recall score (score range: $0-15$ ).

- Paired-associate learning test (associative memory; score range: 0-12) and logical memory (trial 1 and trial 2; score range: 0-12) subtests from the Cognitive Efficiency Profile. ${ }^{41}$
- TMT-A and TMT-B ${ }^{31}$ assessing processing speed, attention, and executive functions. The completion time was recorded. A completion time of 300 seconds was assigned if a subject failed to complete the TMT-B.

- Symbol Digit Modalities Test (SDMT) of the Wechsler Adult Intelligent Scale-Fourth Edition (WAIS-IV) ${ }^{29}$ measuring processing speed/attentional control (score range: 0-133).

- Backward Digit Span from the WAIS-IV ${ }^{29}$ assessing working memory (score range: 0-14).

- Verbal fluency ("letter P" for phonemic fluency and "animals" for categorical fluency, 2 minutes) measuring verbal ability and executive control. ${ }^{30}$

- Rey-Osterrieth Complex Figure (ROCF) assessing planning and organization, visual memory, and visuospatial processing. ${ }^{42,43}$ Copy completion time, copy score (score range: 0-36), and 3-minute immediate recall score (score range: 0-36) were recorded.

To reduce the risk of test performances improving following CCS because of the learning effect of repeated assessments, parallel versions were used when available.

\section{Psychosocial measures}

- French versions of the Cognitive Difficulties Scale ${ }^{44}$ assessing subjective memory complaints.

- Geriatric Depression Scale (30-item GDS) ${ }^{45}$ assessing symptoms of depression.

- Goldberg Anxiety Scale ${ }^{46}$ assessing symptoms of anxiety.

- Quality of life was assessed using the Quality of Life Scale for older French People (Echelle de Qualité de Vie adaptée aux Personnes Agées; EQVPA). ${ }^{47}$

- French version of the Rosenberg Self-esteem Scale assessing global self-worth. ${ }^{48}$

- Level of motivation, with regard to interest in participating in this study and in future interventions like this, was assessed using a 20-point Likert Scale (not at all $=0$ to very motivated=20).

\section{Statistical analysis}

Data were summarized in the form of mean and SD for quantitative variables and count and percentage for categorical variables. Baseline characteristics and assessments were compared between the two groups (MCI-non-WMH vs MCIWMH) using Fisher's exact test. The main analysis focused on postintervention assessment and secondary analysis on follow-up assessment. Differences between postintervention (T3) and baseline (T0) and between follow-up (T6) and baseline (T0) were compared within each group using paired 
$t$-tests. Intervention effects at T3 and T6 were compared between the two groups, using analysis of covariance, with the baseline score being the covariate and groups being the factor. All models were adjusted for age, sex, education, and hippocampal atrophy. To estimate the magnitude of difference between the two groups with regard to change over time, effect size index was calculated using Cohen's $f^{2}$. Effect size is categorized as small $\left(f^{2}=0.10\right)$, medium $\left(f^{2}=0.25\right)$, or large $\left(f^{2}=0.40\right){ }^{49}$

All tests were two-sided, with a significance level of 0.05. No corrections were made for multiple comparisons because of the exploratory nature of the analyses. Analyses were carried out using R statistical software version 3.3.2 (R Foundation for Statistical Computing, Vienna, Austria).

\section{Results}

The MCI-non-WMH group included 29 MCI subjects who presented no or minimal WMH (grades 0 and 1), and the MCI-WMH group was composed of $22 \mathrm{MCI}$ subjects who presented moderate-to-severe WMH (grades 2 and 3). Demographics and clinical data for the two groups are summarized in Table 1. There were no significant differences in sex, education, premorbid intelligence, or presence of hippocampal atrophy between the two groups. However, MCI-WMH subjects were significantly older than those in the MCI-non-WMH group.

\section{Baseline assessments}

Neuropsychological and psychosocial scores are summarized in Table 2. The MCI-non-WMH group outperformed the MCI-WMH group on the MMSE ( $p=0.039$ ), two measures of the RAVLT ( $p=0.039$ and 0.029 for immediate recall and delayed recall, respectively) and ROCF copy completion time ( $p=0.033$ ). No significant difference was found on other measures.

\section{Cognitive and psychosocial changes after the intervention within each group}

Changes in scores for cognitive and psychosocial measures after the intervention are presented in Tables 3 and 4.

From baseline to postintervention, the MCI-WMH group showed significant improvement on the MMSE ( $p=0.027$ ), the paired-associate learning test $(p=0.0003)$, TMT-A $(p=0.041)$, TMT-B $(p=0.035)$, and motivation $(p=0.001)$. The MCI-non-WMH group improved on a higher number of outcome measures, namely the paired-associate learning test $(p<0.0001)$, TMT-A ( $p=0.054)$, Backward Digit Span ( $p=0.023)$, digit symbol test $(p=0.037)$, ROCF copy $(p=0.007)$, ROCF recall ( $p=0.001)$, phonemic fluency ( $p=0.007$ ), categorical fluency ( $p=0.001$ ), and motivation $(p=0.01$ ).

Between the baseline and the 3-month follow-up, improvement in the MCI-WMH group was found for the immediate and the delayed recall of the RAVLT ( $p=0.0005$ and 0.0008 , respectively), the paired-associate learning test ( $p=0.0001)$, TMT-A (0.016), and ROCF copy score ( $p=0.015$ ). Once again, improvement on a higher number of outcome measures was found in the MCI-non-WMH group, namely on the paired-associate learning test $(p<0.0001)$, TMT-A ( $p=0.01)$, ROCF copy $(p=0.021)$, ROCF recall $(p<0.0001)$, categorical fluency $(p=0.033)$, and motivation $(p=0.009)$.

Figures 2 and 3 depict the performances for the immediate recall and the delayed recall of the RAVLT in the two groups, at the three assessment points. The performances for the paired-associate memory test and categorical fluency are depicted in Figures 4 and 5, respectively.

\section{Differences between groups in changes on outcome measures}

At postintervention assessment, CCS had a more beneficial effect on the MCI-non-WMH group than on the MCI-WMH

Table I Baseline characteristics and demographics of the subjects

\begin{tabular}{llll}
\hline Characteristics & $\begin{array}{l}\text { MCI-WMH } \\
(\mathbf{n = 2 2})\end{array}$ & $\begin{array}{l}\text { MCI-non-WMH } \\
(\mathbf{n}=\mathbf{2 9})\end{array}$ & p-value \\
\hline Age (years) & $76.6(6.3)$ & $74.2(6.0)$ & $0.03 *$ \\
Sex, female, $\mathrm{n}(\%)$ & $19(86.4)$ & $20(69)$ & 0.26 \\
fNART & $31.5(4.4)$ & $54.5(12)$ & 0.99 \\
Education level, >college degree, $\mathrm{n}(\%)$ & $13(59.1)$ & $17(58.6)$ & 0.94 \\
Hippocampal atrophy, $\mathrm{n}(\%)$ & $14(48.3)$ & $10(45.5)$ & 0.99 \\
Right $\geq 3$ severity & $2(9.1)$ & $2(6.9)$ & 0.93 \\
Left $\geq 3$ severity & $2(9.1)$ & $3(10.3)$ & 0.91 \\
\hline
\end{tabular}

Notes: Values are given as mean (SD) or n (\%); hippocampal atrophy: absence of hippocampal atrophy; * $p<0.05$.

Abbreviations: fNART, French version of Adult Reading Test; $\mathrm{MCl}-\mathrm{WMH}$, mild cognitive impairment with moderate or severe white matter hyperintensities; MCl-non$\mathrm{WMH}, \mathrm{MCl}$ with no or little white matter hyperintensities; ROCF, Rey-Osterrieth Complex Figure. 
Table 2 Comparison between two groups on cognitive and psychosocial measures at baseline assessment

\begin{tabular}{|c|c|c|c|}
\hline Variable & MCI-WMH (n=22) & MCI-non-WMH (n=29) & p-values \\
\hline \multicolumn{4}{|l|}{ Cognitive measures } \\
\hline MMSE & $26.5 \pm 2.5$ & $27.9 \pm 1.8$ & $0.039 *$ \\
\hline RAVLT-immediate recall & $41.3 \pm 12.9$ & $49 \pm 12.8$ & $0.039 *$ \\
\hline RAVLT-delayed recall & $7.8 \pm 4.4$ & $10.5 \pm 4$ & $0.029 *$ \\
\hline Logic memory-trial I & $10.3 \pm 4.5$ & $12 \pm 4$ & 0.17 \\
\hline Logic memory-trial 2 & $14 \pm 5.5$ & $15.4 \pm 4.2$ & 0.34 \\
\hline Paired-associated learning test & $3.9 \pm 3.2$ & $4.4 \pm 3.2$ & 0.55 \\
\hline TMT-A & $49.3 \pm 18.4$ & $44.3 \pm 11.7$ & 0.28 \\
\hline TMT-B & $143 \pm 62$ & $112.9 \pm 54.5$ & 0.079 \\
\hline Backward Digit Span & $4 \pm 1$ & $4.1 \pm 1$ & 0.59 \\
\hline Symbol Digit Modalities Test & $45.3 \pm 10.2$ & $49.8 \pm 9.9$ & 0.12 \\
\hline ROCF (copy) & $29.7 \pm 4.4$ & $29.7 \pm 4.2$ & 0.98 \\
\hline ROCF (completion time) & $190.9 \pm 73$ & $151.6 \pm 45.4$ & $0.033^{*}$ \\
\hline ROCF (recall) & $12.4 \pm 5.2$ & $12.3 \pm 5.6$ & 0.97 \\
\hline Phonemic verbal fluency & $23.2 \pm 6.6$ & $23.6 \pm 5.9$ & 0.86 \\
\hline Categorical verbal fluency & $22.3 \pm 8.3$ & $24.1 \pm 6.7$ & 0.41 \\
\hline \multicolumn{4}{|l|}{ Psychosocial measures } \\
\hline Motivation & $16.1 \pm 2.9$ & $16 \pm 3.3$ & 0.88 \\
\hline Rosenberg Self-esteem Scale & $29.4 \pm 7.2$ & $3 I .1 \pm 5.8$ & 0.38 \\
\hline EQVPA (Quality of Life Scale) & $9.4 \pm 3.6$ & $10.4 \pm 2.8$ & 0.27 \\
\hline Cognitive Difficulty Scale & $21.4 \pm 6.2$ & $22.2 \pm 7.8$ & 0.66 \\
\hline Geriatric Depression Scale & $11 \pm 5.3$ & $9.4 \pm 6.8$ & 0.35 \\
\hline Goldberg Anxiety Scale & $5.1 \pm 2.1$ & $4.7 \pm 2.5$ & 0.51 \\
\hline
\end{tabular}

Notes: Values are given as mean (SD). $* p<0.05$.

Abbreviations: EQVPA, Échelle de Qualité de Vie adaptée aux Personnes Agées; MCl-WMH, mild cognitive impairment with moderate or severe white matter hyperintensities; MCl-non-WMH, MCl with no or little white matter hyperintensities; MMSE, Mini Mental State Evaluation; RAVLT, Rey Auditory Verbal Learning Test; ROCF, Rey-Osterrieth Complex Figure; TMT, Trail Making Test.

group with regard to improving categorical fluency $(4.6 \pm 6.8$ vs $0.4 \pm 6.4$ points; effect size $=0.37 ; p=0.002$ ).

With regard to the 3-month follow-up assessment, significantly higher score gains were observed in the MCInon-WMH group on the paired-associate learning test $(6.4 \pm 3$ vs $4.7 \pm 3.5$ points; effect size $=0.43 ; p=0.005)$ and categorical fluency $(3.8 \pm 7.8$ vs $-0.7 \pm 6$ points; effect size $=0.55$; $p=0.0003$ ).

\section{Discussion}

In this study, we investigated whether a CCS program induced differential effects in older adults diagnosed with MCI, according to the severity of WMH. All participants attended 24 sessions of the CCS program over a period of 3 months. The main findings were that 1) at baseline, in comparison with the MCI-non-WMH group, the subjects in MCI-WMH group were older and presented lower global cognitive efficiency and worse episodic memory, and needed more time to copy a complex figure; 2) the two groups improved on several cognitive measures after the intervention; 3) the MCI-non-WMH group improved on a higher number of cognitive measure than the MCI-WMH group, suggesting that the CCS program seemed to be more beneficial for MCI subjects without WMH; 4) although two cognitive measures were improved in both groups, the differential improvements for the other cognitive measures depend on the group status.

The baseline differences between the two groups in our study are not surprising. It is reported that WMH is associated not only with older age,${ }^{50}$ but also with impairment of perceptual/processing speed, ${ }^{51,52}$ global cognition, executive functions, working memory, episodic memory, and semantic memory. ${ }^{13,53-55}$

Both groups improved on the paired-associate learning test and the TMT-A at postintervention. The improvement persisted for another 3 months after the intervention had been discontinued. The paired-associate learning test requires several memory strategies, such as semantic processing, visual imagery categorization, association, and organization. ${ }^{56}$ A significant time reduction on the TMT-A suggests an improvement of processing speed. These improvements could be attributed to several cognitive exercises used within the CCS program, which were focused on stimulating these cognitive processes. 


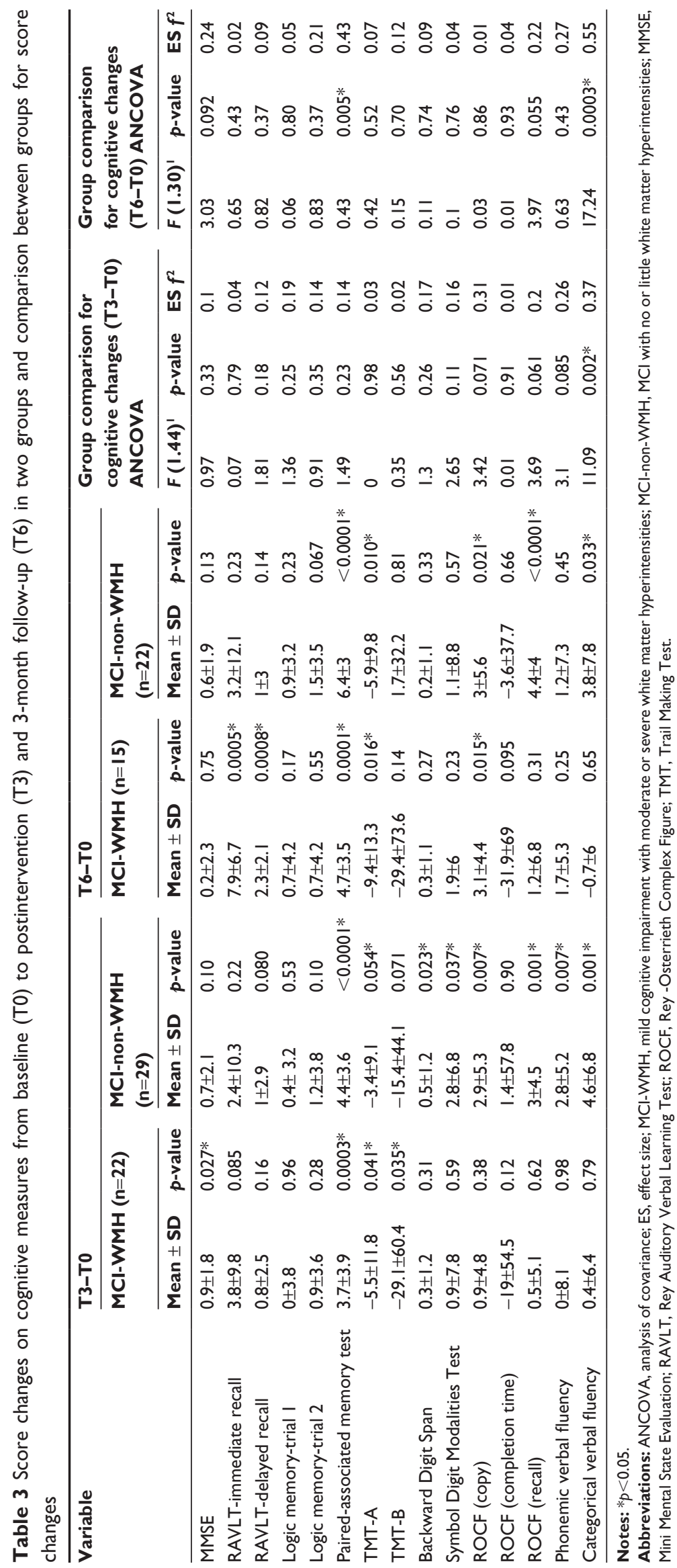




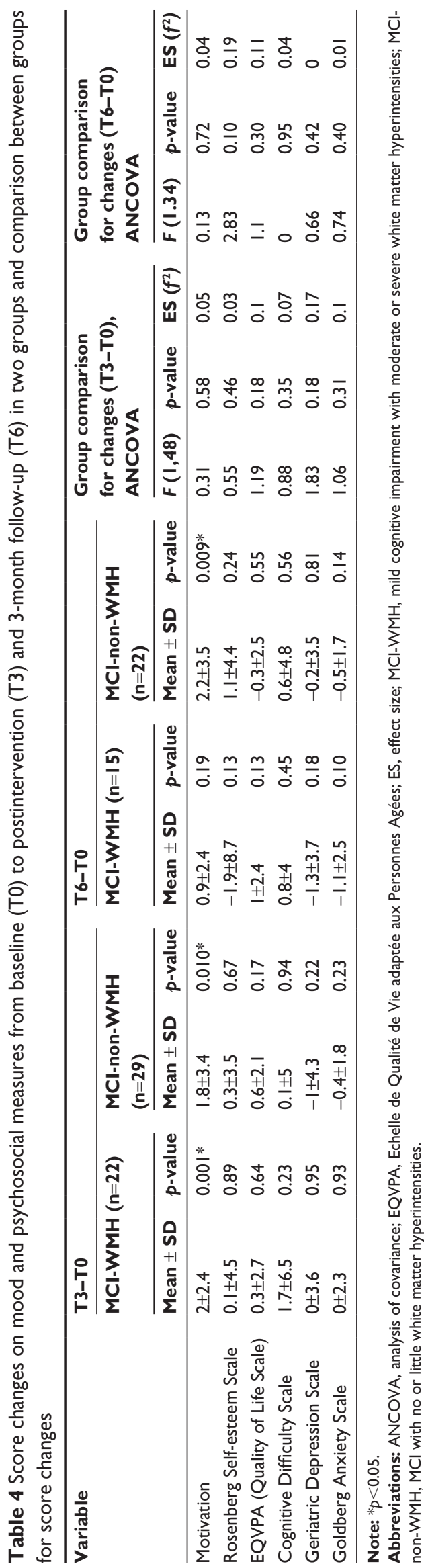

Aside from the two measures mentioned above, the MCIWMH group improved on global cognitive efficiency and motivation at postintervention. However, the improvement was not observed during the 3-month follow-up. It is worth noting that these subjects improved their performance on the immediate and delayed recall of the RAVLT as well as the ROCF copy score during the 3-month follow-up. Compared with MCI-non-WMH subjects, MCI-WMH subjects had impaired retrieval and long-term consolidation processes at baseline. However, they could still improve these cognitive functions, thanks to the CCS intervention, suggesting potential cognitive and brain plasticity in these patients. Previous studies have shown that in both younger and older adulthood, cognitive training can modify white matter microstructure ${ }^{57}$ and that there is a significant link between memory improvement and changes in white matter. ${ }^{58}$ Our findings are in concordance with a recent study on the effects of a training program focusing on attentional processes (weekly 2-hour sessions for 20 weeks) in MCI patients with moderate-tosevere WMH. The authors also found improvements on the immediate recall of the RAVLT and ROCF copy in MCI patients receiving the intervention, compared with the notreatment group. ${ }^{59}$

MCI patients with no or little WMH improved their performance on a higher number of cognitive measures than those with moderate-to-severe WMH at postintervention and during the follow-up assessments. At postintervention, they improved on the Backward Digit Span, the SDMT, and phonemic fluency, although these improvements did not last. However, improvements on copy and recall of the ROCF and categorical fluency were observed both at postintervention and during the 3-month follow-up assessments. Moreover, significantly higher score gains with medium-to-large effect sizes, favoring the MCI-non-WMH group, were observed on the paired-associate memory test during the 3-month follow-up and on categorical fluency both at postintervention and during follow-up assessments. Overall, these findings suggest that MCI patients with WMH did not benefit from the CCS program as much as those with no or little WMH, with regard to enhancing specific cognitive functions. Taken together, our findings suggest that severity of WMH was related to baseline cognitive performance and cognitive improvement induced by a CCS program. These findings conflict with those of a study exploring the effects of working memory training on cognitive functions in MCI subjects and healthy older adults, in which authors found that hippocampal atrophy, instead of WMH, may be a predictor of cognitive training outcome. ${ }^{9}$ 


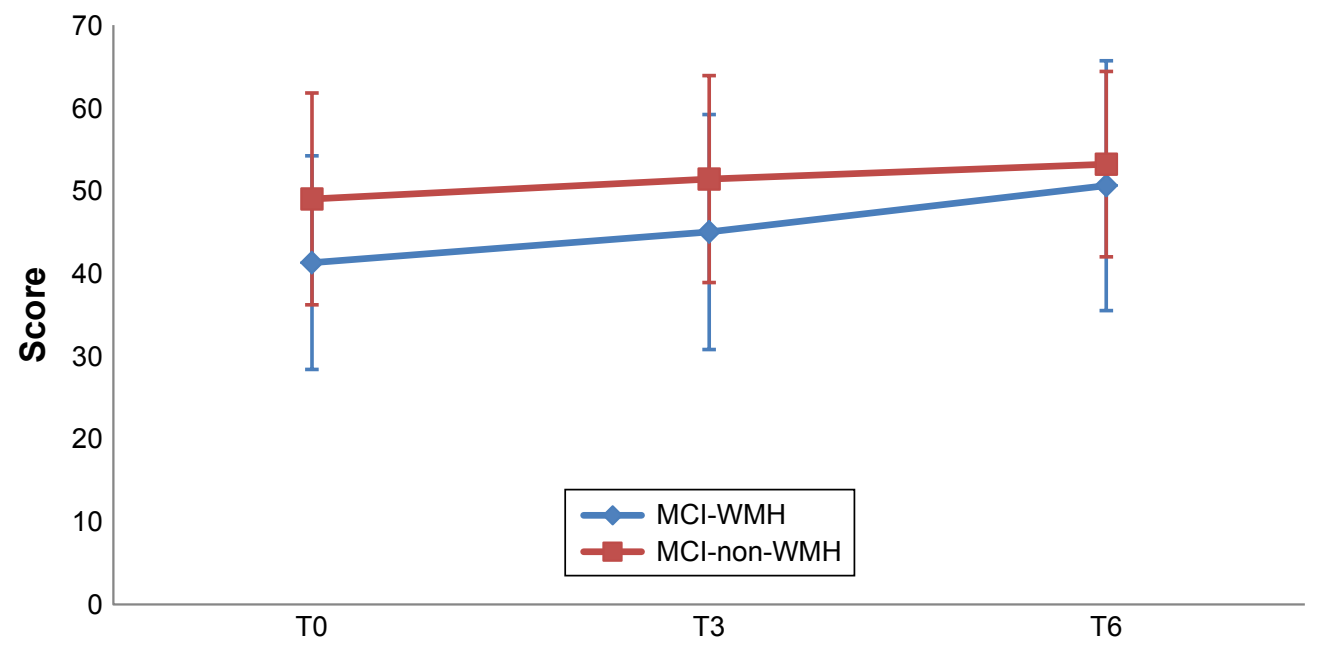

Figure 2 RAVLT the sum of five immediate recall scores in the $\mathrm{MCl}-\mathrm{WMH}$ vs $\mathrm{MCl}$-non-WMH at baseline (T0), postintervention (T3), and 3-month follow-up (T6). Abbreviations: $\mathrm{MCl}$, mild cognitive impairment; $\mathrm{MCl}-\mathrm{WMH}, \mathrm{MCl}$ with moderate or severe white matter hyperintensities; $\mathrm{MCl}$-non-WMH, $\mathrm{MCl}$ with no or little white matter hyperintensities; RAVLT, Rey Auditory Verbal Learning Test.

Finally, the two groups did not improve on psychosocial measures, except for motivation, which was initially high, being enhanced after the intervention for both groups. The enhancement persisted through to the follow-up assessment only for the MCI-non-WMH group. This finding suggests that this short-term cognitive intervention was not effective with regard to enhancing psychosocial functioning in MCI subjects.

\section{Limitations}

One of the limitations of the study is the lack of a control group, which did not receive the CCS intervention. However, our principal objective was to compare the effects of the CCS program on two clinical samples in order to understand if
WMH affect intervention outcome. A randomized controlled trial is required to determine the efficacy of the CCS as a clinical intervention. In addition, the small sample size keeps us from analyzing the intervention effects according to the periventricular or deep nature of the $\mathrm{WMH}$, as some studies reported that these two types of lesions may differentially impact the clinical presentation. ${ }^{52,60-63}$

\section{Conclusions}

This study constitutes a preliminary exploration, which aims to highlight the importance of considering WMH in interventions in MCI patients. Our findings suggest that both MCI subjects with and without WMH could benefit from this type

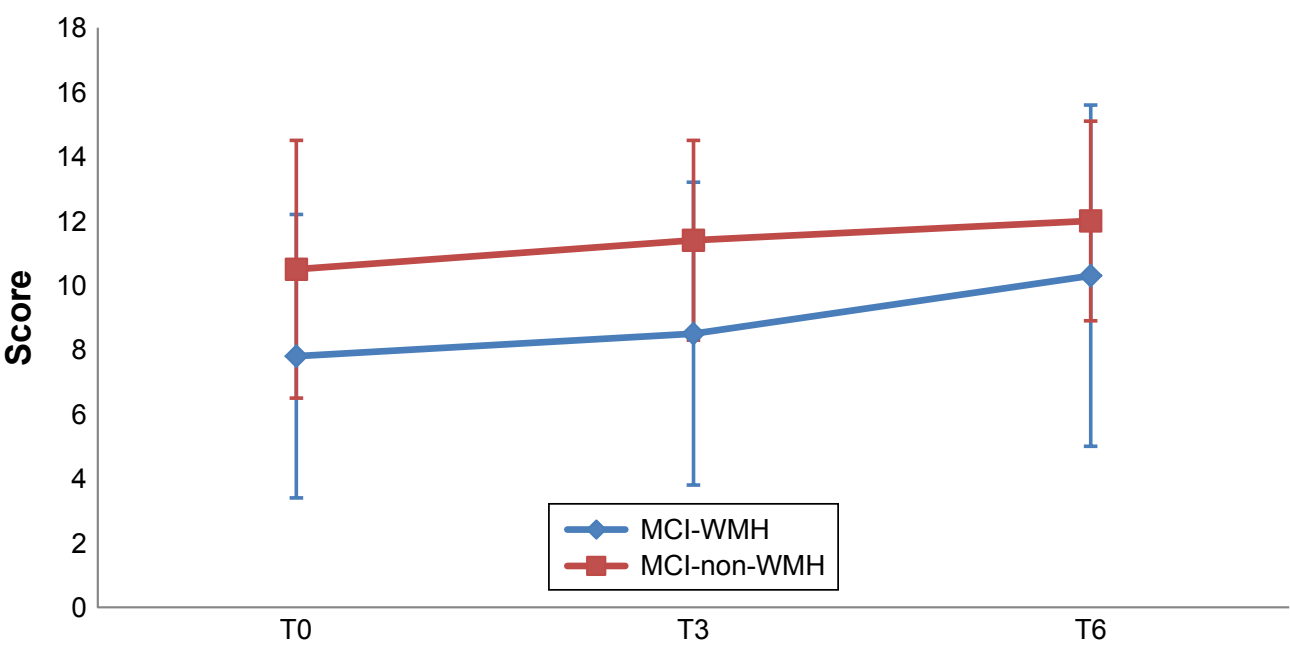

Figure 3 RAVLT delayed recall scores in the MCl-WMH vs MCl-non-WMH at baseline (T0), postintervention (T3), and 3-month follow-up (T6).

Abbreviations: $\mathrm{MCl}$, mild cognitive impairment; $\mathrm{MCl}-\mathrm{WMH}, \mathrm{MCl}$ with moderate or severe white matter hyperintensities; $\mathrm{MCl}$-non- $\mathrm{WMH}$, $\mathrm{MCl}$ with no or little white matter hyperintensities; RAVLT, Rey Auditory Verbal Learning Test. 


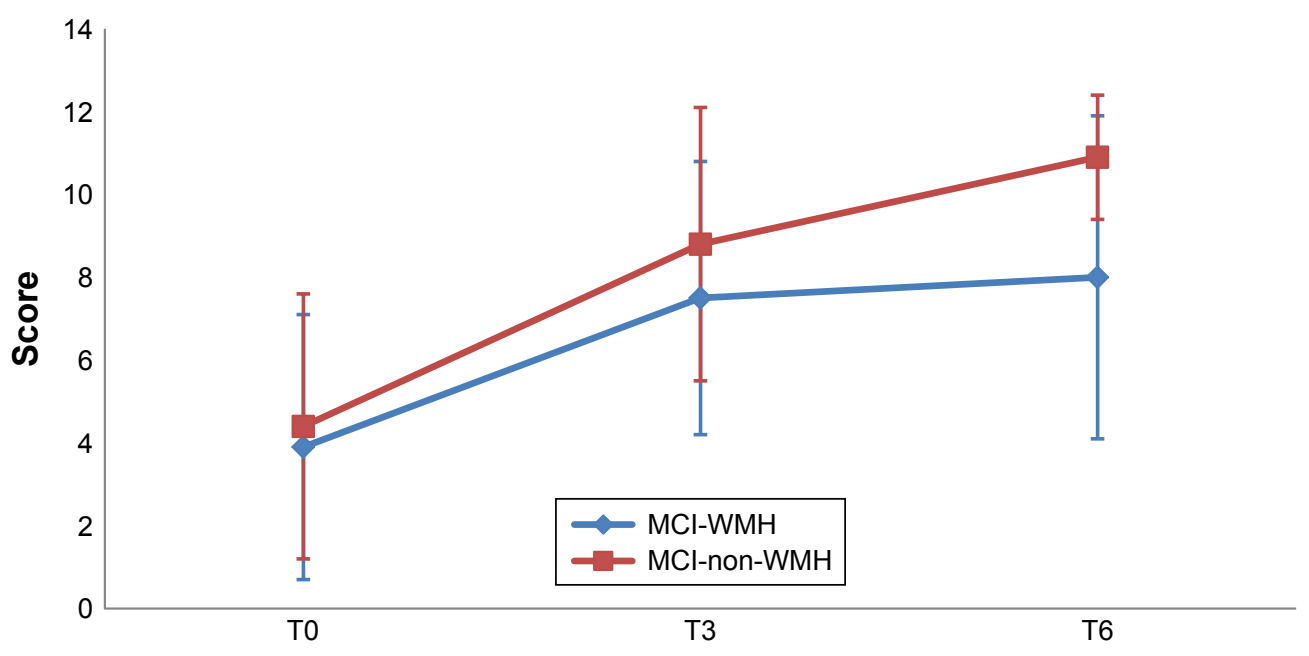

Figure 4 Paired-associate memory test scores in the $\mathrm{MCl}-\mathrm{WMH}$ vs $\mathrm{MCl}$-non-WMH at baseline (T0), postintervention (T3), and 3-month follow-up (T6).

Abbreviations: $\mathrm{MCl}$, mild cognitive impairment; $\mathrm{MCl}-\mathrm{WMH}, \mathrm{MCl}$ with moderate or severe white matter hyperintensities; $\mathrm{MCl}$-non- $\mathrm{WMH}$, $\mathrm{MCl}$ with no or little white matter hyperintensities.

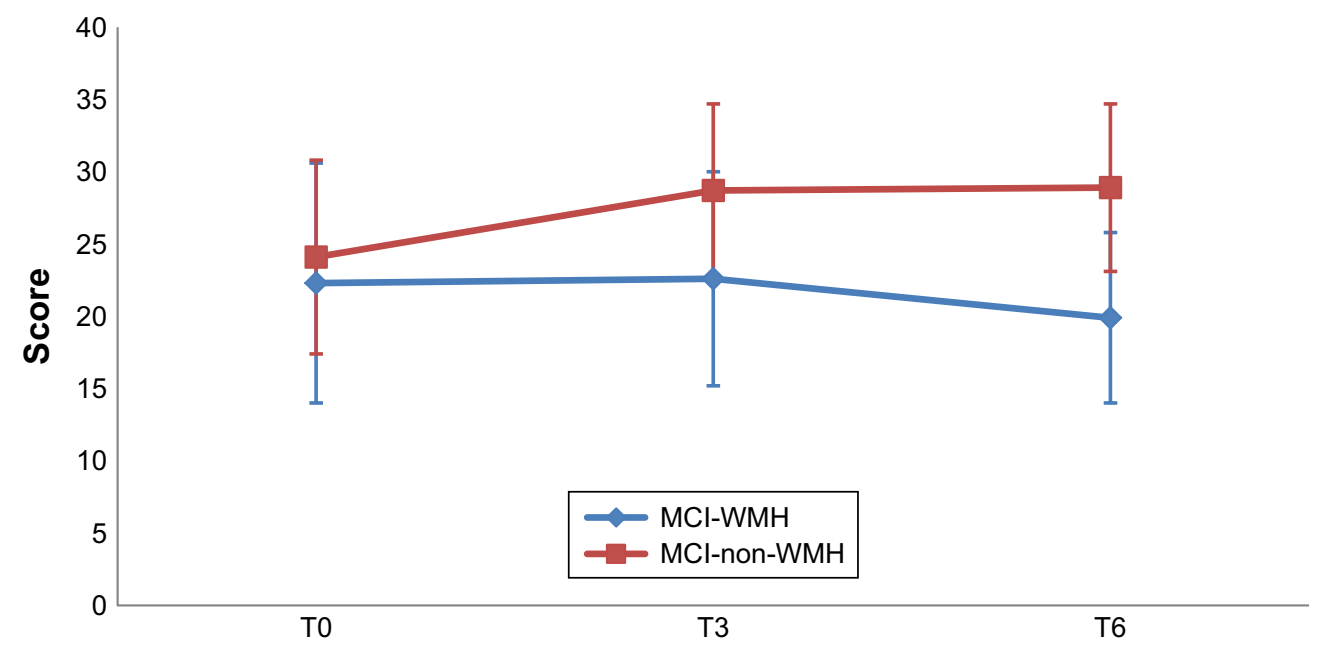

Figure 5 Categorical verbal fluency scores in the $\mathrm{MCl}-\mathrm{WMH}$ vs $\mathrm{MCl}$-non-WMH at baseline (T0), postintervention (T3), and 3-month follow-up (T6).

Abbreviations: $\mathrm{MCl}$, mild cognitive impairment; $\mathrm{MCl}-\mathrm{WMH}, \mathrm{MCl}$ with moderate or severe white matter hyperintensities; $\mathrm{MCl}-\mathrm{non}-\mathrm{WMH}$, $\mathrm{MCl}$ with no or little white matter hyperintensities.

of CCS program, with improvements being observed within several cognitive domains, and some improvements being maintained through to a short-term follow-up. However, the differential effects in the two groups suggest that brain lesions could influence intervention outcomes. MCI-non-WMH subjects improved on a higher number of cognitive measures than MCI-WMH subjects, for whom no improvement was observed for certain cognitive functions. Interestingly, our findings did show that MCI-WMH subjects could improve on some components of executive functions, processing speed, and memory, suggesting potential cognitive plasticity in these patients, who are at higher risk of worsening cognitive decline with the progression of lesions, and of developing $\mathrm{AD}$ and dementia. These findings are encouraging and should be confirmed in a randomized controlled trial. We also suggest that in future cognitive intervention studies, brain lesions, such as hippocampal atrophy and WMH, should be taken into consideration when analyzing intervention effects on patients with MCI.

\section{Acknowledgments}

We would like to thank the Fondation des Gueules Cassées (FGC) for their financial support in the form of a doctoral scholarship awarded to Leila Djabelkhir-Jemmi. Thanks to KODRO for supporting this thesis through the use of Kodro software, and to all participants for their contribution to this research. 


\section{Disclosure}

The authors report no conflicts of interest in this work.

\section{References}

1. Farias ST, Mungas D, Reed BR, et al. The measurement of everyday cognition (ECog): scale development and psychometric properties. Neuropsychology. 2008;22(4):531-544.

2. Petersen RC, Smith GE, Waring SC, Ivnik RJ, Tangalos EG, Kokmen E. Mild cognitive impairment: clinical characterization and outcome. Arch Neurol. 1999;56(3):303-308.

3. Clare L, Woods RT. Cognitive training and cognitive rehabilitation for people with early-stage Alzheimer's disease: a review. Neuropsychol Rehabil. 2004;14(4):385-401.

4. Li H, Li J, Li N, Li B, Wang P, Zhou T. Cognitive intervention for persons with mild cognitive impairment: a meta-analysis. Ageing Res Rev. 2011;10(2):285-296.

5. Reijnders J, van Heugten C, van Boxtel M. Cognitive interventions in healthy older adults and people with mild cognitive impairment: a systematic review. Ageing Res Rev. 2013;12(1):263-275.

6. Gagnon LG, Belleville S. Training of attentional control in mild cognitive impairment with executive deficits: results from a double-blind randomised controlled study. Neuropsychol Rehabil. 2012;22(6): 809-835.

7. Herrera C, Chambon C, Michel BF, Paban V, Alescio-Lautier B. Positive effects of computer-based cognitive training in adults with mild cognitive impairment. Neuropsychologia. 2012;50(8):1871-1881.

8. Oskoei AS, Nejati V, Ajilchi B. The effectiveness of cognitive rehabilitation on improving the selective attention in patients with mild cognitive impairment. J Behav Brain Sci. 2013;3(6):474-478.

9. Vermeij A, Claassen JA, Dautzenberg PL, Kessels RP. Transfer and maintenance effects of online working-memory training in normal ageing and mild cognitive impairment. Neuropsychol Rehabil. 2016; 26(5-6):783-809.

10. Vaportzis E, Martin M, Gow AJ. A tablet for healthy ageing: the effect of a tablet computer training intervention on cognitive abilities in older adults. Am J Geriatr Psychiatry. 2017;25(8):841-851.

11. RodakowskiJ, SaghafiE, Butters MA, SkidmoreER. Non-pharmacological interventions for adults with mild cognitive impairment and early stage dementia: an updated scoping review. Mol Aspects Med. 2015, 44:38-53.

12. Simon SS, Yokomizo JE, Bottino CM. Cognitive intervention in amnestic mild cognitive impairment: a systematic review. Neurosci Biobehav Rev. 2012;36(4):1163-1178.

13. Boyle PA, Yu L, Fleischman DA, et al. White matter hyperintensities, incident mild cognitive impairment, and cognitive decline in old age. Ann Clin Transl Neurol. 2016;3(10):791-800.

14. Brickman AM, Provenzano FA, Muraskin J, et al. Regional white matter hyperintensity volume, not hippocampal atrophy, predicts incident Alzheimer disease in the community. Arch Neurol. 2012;69(12): 1621-1627.

15. Rossi R, Geroldi C, Bresciani L, et al. Clinical and neuropsychological features associated with structural imaging patterns in patients with mild cognitive impairment. Dement Geriatr Cogn Disord. 2007;23(3): $175-183$

16. Lee JM, Markus HS. Does the white matter matter in Alzheimer disease and cerebral amyloid angiopathy? Neurology. 2006;66(1):6-7.

17. Luchsinger JA, Brickman AM, Reitz C, et al. Subclinical cerebrovascular disease in mild cognitive impairment. Neurology. 2009;73(6): 450-456.

18. Provenzano FA, Muraskin J, Tosto G, et al; Alzheimer's disease neuroimaging initiative. White matter hyperintensities and cerebral amyloidosis: necessary and sufficient for clinical expression of Alzheimer disease? JAMA Neurol. 2013;70(4):455-461.

19. Pugh KG, Lipsitz LA. The microvascular frontal-subcortical syndrome of aging. Neurobiol Aging. 2002;23(3):421-431.
20. Tullberg M, Fletcher E, DeCarli C, et al. White matter lesions impair frontal lobe function regardless of their location. Neurology. 2004;63(2): 246-253.

21. Grambaite R, Selnes P, Reinvang I, et al. Executive dysfunction in mild cognitive impairment is associated with changes in frontal and cingulate white matter tracts. J Alzheimers Dis. 2011;27(2):453-462.

22. Habes M, Erus G, Toledo JB, et al. White matter hyperintensities and imaging patterns of brain ageing in the general population. Brain. 2016;139(4):1164-1179.

23. Gunning-Dixon FM, Raz N; American Psychological Association. The cognitive correlates of white matter abnormalities in normal aging: a quantitative review. Neuropsychology. 2000;14(2):224-232.

24. Lam CLM, Yiend J, Lee TMC. Imaging and neuropsychological correlates of white matter lesions in different subtypes of mild cognitive impairment: a systematic review. Neuro Rehabilitation. 2017;41(1): 189-204.

25. Yoshita M, Fletcher E, Harvey D, et al. Extent and distribution of white matter hyperintensities in normal aging, MCI, and AD. Neurology. 2006;67(12):2192-2198.

26. Petersen RC. Mild cognitive impairment as a diagnostic entity. J Intern Med. 2004;256(3):183-194.

27. Van der Linden M, Coyette F, Poitrenaud J, et les membres du GREMEM. L'épreuve de rappel libre/rappel indicé à 16 items (RL/RI-16). In: Van der Linden M, Adam S, Agniel A, et les membres du GREMEM ed. L'Evaluation Des Troubles De La Mémoire. Présentation De Quatre Tests De Mémoire Episodique (avec leur étalonnage). Marseille: Solal; 2004:25-47.

28. Dubois B, Slachevsky A, Litvan I, Pillon B. The FAB: a Frontal Assessment Battery at bedside. Neurology. 2000;55(11):1621-1626.

29. Wechsler D. Wechsler Adult Intelligence Scale - Fourth Edition (WAIS-IV). San Antonio, TX, USA: Pearson; 2008.

30. Lezak MD, Howieson DB, Loring DW. Neuropsychological Assessment. New York, NY, USA: Oxford University Press; 2004.

31. Reitan RM. Trail Making Test: Manual for administration and scoring. Tucson, AZ, USA: Reitan Neuropsychology Laboratory; 1992.

32. Deloche G, Hannequin D. DO 80: Test De Dénomination Orale d'Images [DO 80: Oral Denomination Test Images]. Paris: Les Editions du Centre de Psychologie Appliquée (ECPA); 1997. French.

33. Mahieux-Laurent F, Fabre C, Galbrun E, Dubrulle A, Moroni C. Validation d'une batterie brève d'évaluation des praxies gestuelles pour consultation Mémoire. Évaluation chez 419 témoins, 127 patients atteints de troubles cognitifs légers et 320 patients atteints d'une démence. [Validation of a brief screening scale evaluating praxic abilities for use in memory clinics. Evaluation in 419 controls, 127 mild cognitive impairment and 320 demented patients]. Rev Neurol. 2009;165(6):560-567. French.

34. Fazekas F, Chawluk JB, Alavi A, Hurtig HI, Zimmerman RA. MR signal abnormalities at $1.5 \mathrm{~T}$ in Alzheimer's dementia and normal aging. $\mathrm{Am}$ J Roentgenol. 1987;149(2):351-356.

35. De Rotrou J. Méthodologie pour une stimulation psychologique des fonctions cognitives. [Methodology for a psychological stimulation of cognitive functions]. Paper presented at: Démences du sujet âgé et environnement: actes du 2e colloque, les 1985 [Dementia of the elderly subject and environment: Proceedings of the 2nd Symposium, 1985] Paris, France. French.

36. De Rotrou J. Cognitive stimulation and education. Gérontol Soc. 2001;24(97):175-192.

37. Breuil V, De Rotrou J, Forette F, et al. Cognitive stimulation of patients with dementia: preliminary results. Int J Geriatr Psychiatry. 1994;9(3):211-217.

38. Mackinnon A, Mulligan R. [The estimation of premorbid intelligence levels in French speakers]. Encephale. 2005;31(1 Pt 1):31-43. French.

39. Folstein MF, Folstein SE, McHugh PR. "Mini-mental state". A practical method for grading the cognitive state of patients for the clinician. J Psychiatr Res. 1975;12(3):189-198.

40. Rey A. L'examen clinique en psychologie [Psychological Clinical Examination]. Paris: Presses Universitaires de France; 1964. French. 
41. De Rotrou J, Forette F, Hervy MP, et al. The cognitive efficiency profile: description and validation in patients with Alzheimer's disease. Int $J$ Geriatr Psychiatry. 1991;6(7):501-509.

42. Rey A. L'examen psychologique dans les cas d'encéphalopathie traumatique. [Psychological examination in cases of traumatic encephalopathy]. Arch Psychol. 1941;28:286-340. French.

43. OsterriethPA. Thetest decopied'une figure complexe: contributionàl'étude de la perception et de la mémoire. [Test of copying a complex figure; contribution to the study of perception and memory]. Arch Psychol. 1944;30: 286-356. French.

44. Poitrenaud J, Israel L, Barrere H, Le Roc'h K. Version française de l'échelle de difficulties cognitive de McNair et Khan. [French version of McNair and Khan's Cognitive Difficulty Scale]. In: Michel BF, Derouesne C, Gely-Nargeot MC, editors. De la Plainte Mnésique à la Maladie d'Alzheimer. [From the Mnemic Complaint to Alzheimer's disease]. Marseille: Solal; 1997:159-177. French.

45. Yesavage JA, Brink TL, Rose TL, et al. Development and validation of a geriatric depression screening scale: a preliminary report. J Psychiatr Res. 1982;17(1):37-49.

46. Goldberg D, Bridges K, Duncan-Jones P, Grayson D. Detecting anxiety and depression in general medical settings. BMJ. 1988;297(6653): 897-899.

47. Petit S, Bergua V, Peres K, Bouisson J, Koleck M. Élaboration et validation d'une échelle de qualité de vie adaptée aux personnes âgées (EQVPA). [Development and validation of a quality of life scale adapted to the elderly]. Gériatr Psychol Neuropsychiatr Vieil. 2014;12(4):379-386. French.

48. Rosenberg M, Black SR, Self-Esteem W. The Urban School Child. Washington, DC, USA: American Sociological Association; 1971.

49. Cohen J. Statistical Power Analysis for the Behavioral Sciences. 2nd ed. Hillsdale, NJ, USA: Lawrence Erlbaum Associates; 1988.

50. Basile AM, Pantoni L, Pracucci G, et al; LADIS Study Group. Age, hypertension, and lacunar stroke are the major determinants of the severity of age-related white matter changes. The LADIS (Leukoaraiosis and Disability in the Elderly) Study. Cerebrovasc Dis. 2006;21(5-6): 315-322.

51. Arvanitakis Z, Fleischman DA, Arfanakis K, Leurgans SE, Barnes LL, Bennett DA. Association of white matter hyperintensities and gray matter volume with cognition in older individuals without cognitive impairment. Brain Struct Funct. 2016;221(4):2135-2146.
52. van den Heuvel DM, ten Dam VH, de Craen AJ, et al. Increase in periventricular white matter hyperintensities parallels decline in mental processing speed in a non-demented elderly population. J Neurol Neurosurg Psychiatry. 2006;77(2):149-153.

53. Au R, Massaro JM, Wolf PA, et al. Association of white matter hyperintensity volume with decreased cognitive functioning: the Framingham Heart Study. Arch Neurol. 2006;63(2):246-250.

54. Hedden T, Mormino EC, Amariglio RE, et al. Cognitive profile of amyloid burden and white matter hyperintensities in cognitively normal older adults. J Neurosci. 2012;32(46):16233-16242.

55. Moon SY, de Souto Barreto P, Chupin M, et al. Associations between white matter hyperintensities and cognitive decline over three years in non-dementia older adults with memory complaints. J Neurol Sci. 2017;379:266-270.

56. Wenisch E, Cantegreil-Kallen I, De Rotrou J, et al. Cognitive stimulation intervention for elders with mild cognitive impairment compared to normal aged subjects: preliminary results. Aging Clin Exp Res. 2007;19(4): 316-322.

57. Lovden M, Bodammer NC, Kuhn S, et al. Experience-dependent plasticity of white-matter microstructure extends into old age. Neuropsychologia. 2010;48(13):3878-3883.

58. Engvig A, Fjell AM, Westlye LT, et al. Memory training impacts shortterm changes in aging white matter: a longitudinal diffusion tensor imaging study. Hum Brain Mapp. 2012;33(10):2390-2406.

59. Pantoni L, Poggesi A, Diciotti S, et al. Effect of attention training in mild cognitive impairment patients with subcortical vascular changes: the RehAtt Study. J Alzheimers Dis. 2017;60(2):615-624.

60. Makino T, Umegaki H, Suzuki Y, et al. Relationship between small cerebral white matter lesions and cognitive function in patients with Alzheimer's disease and amnestic mild cognitive impairment. Geriatr Gerontol Int. 2014;14(4):819-826.

61. Delano-Wood L, Abeles N, Sacco JM, Wierenga CE, Horne NR, Bozoki A. Regional white matter pathology in mild cognitive impairment. Stroke. 2008;39(3):794-799.

62. De Groot JC, De Leeuw FE, Oudkerk M, et al. Periventricular cerebral white matter lesions predict rate of cognitive decline. Ann Neurol. 2002; 52(3):335-341.

63. Smith EE, Salat DH, Jeng J, et al. Correlations between MRI white matter lesion location and executive function and episodic memory. Neurology. 2011;76(17):1492-1499.
Clinical Interventions in Aging

\section{Publish your work in this journal}

Clinical Interventions in Aging is an international, peer-reviewed journal focusing on evidence-based reports on the value or lack thereof of treatments intended to prevent or delay the onset of maladaptive correlates of aging in human beings. This journal is indexed on PubMed Central, MedLine,

\section{Dovepress}

CAS, Scopus and the Elsevier Bibliographic databases. The manuscript management system is completely online and includes a very quick and fair peer-review system, which is all easy to use. Visit http://www.dovepress. com/testimonials.php to read real quotes from published authors. 